\title{
Adult Acute Myeloid Leukemia with Recurrent Genetic Abnormalities
}

National Cancer Institute

\section{Source}

National Cancer Institute. Adult Acute Myeloid Leukemia with Recurrent Genetic

Abnormalities. NCl Thesaurus. Code C68700.

An acute myeloid leukemia with recurrent genetic abnormalities occurring in adults. 